\title{
Marked Regression of Pulmonary Rheumatoid Nodules Under Etanercept Therapy
}

GAELLE DEROT, MD; ANDRE MARINI-PORTUGAL, MD; BERNARD MAITRE, MD, Department of Pneumology; PASCAL CLAUDEPIERRE, MD, Department of Rheumatology, Henri Mondor Teaching Hospital, AP-HP, Créteil, France. Address reprint requests to Prof. P. Claudepierre, Service de Rhumatologie, Hôpital Henri Mondor, 51 Avenue du Maréchal de Lattre de Tassigny, 94010 Créteil Cedex, France. E-mail: pascal.claudepierre@ hmn.aphp.fr; J Rheumatol 2009;36:469-71; doi:10.3899/jrheum.080557

A 60-year-old woman with rheumatoid arthritis had 4 pulmonary rheumatoid nodules with unchanged size since 1999 that appeared during methotrexate (MTX) treatment (Figure 1A). MTX was stopped. Because of persistent inflammatory joint pain with functional impairment, etanercept monotherapy ( $25 \mathrm{mg}$ twice a week) was started in February 2003. After 21 months of treatment, in November 2004, the joint symptoms were markedly improved and a substantial reduction in the size of the pulmonary nodules was noted on the computed tomography scan (Figure 1B). Further reductions were visible in November 2006 (Figure 1C) and March 2008 (Figure 1D).

To our knowledge, this is the first reported case of shrinkage of pulmonary rheumatoid nodules during therapy with tumor necrosis factor- $\alpha$ (TNF- $\alpha$ ) antagonist. Very little is known about the potential effects of TNF- $\alpha$ antagonists on rheumatoid nodules. Few cases of development or enlargement of pulmonary nodules have been published ${ }^{1}$. Several of these patients had high disease activity scores, leaving open the possibility that the nodules reflected a delayed or inadequate response to treatment. Moreover, the time from initiation of TNF- $\alpha$ antagonist to development of nodules varied widely. Therefore, a role for the disease, rather than the treatment, in the development or enlargement of rheumatoid nodules cannot be ruled out.

A favorable effect on the nodules is consistent with the similarities in tissue composition between rheumatoid nodules and the rheumatoid synovium, both of which contain TNF- $\alpha^{2}$. In keeping with this possibility, no effect of TNF- $\alpha$ antagonist therapy on rheumatoid nodules was noted in a small case series ${ }^{3}$.

\section{REFERENCES}

1. Kekow J, Welte T, Kellner U, Pap T. Development of rheumatoid nodules during anti-tumor necrosis factor alpha therapy with etanercept. Arthritis Rheum 2002;46:843-4.

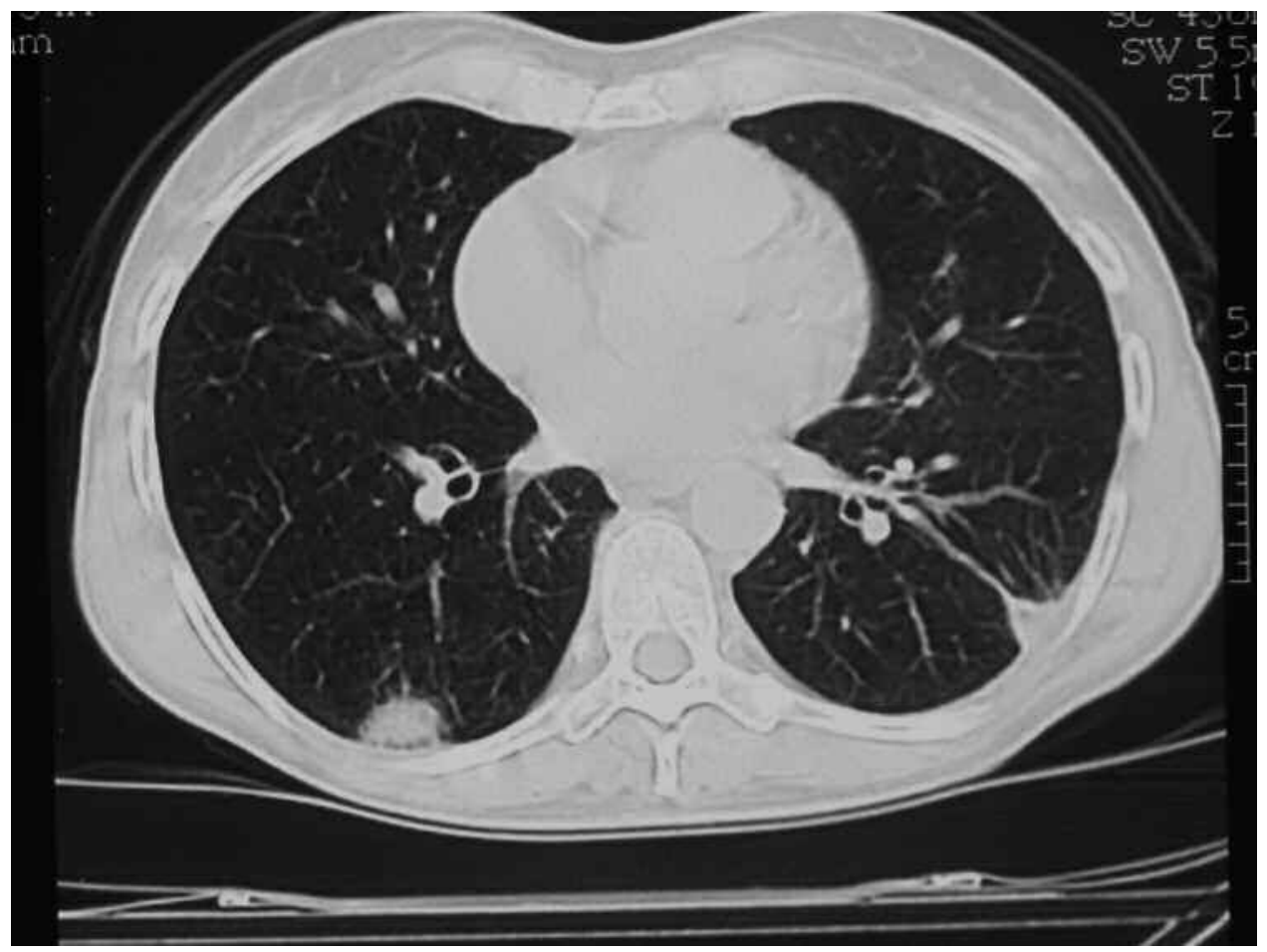

Figure 1A. January 2003; 1 month before etanercept therapy. 


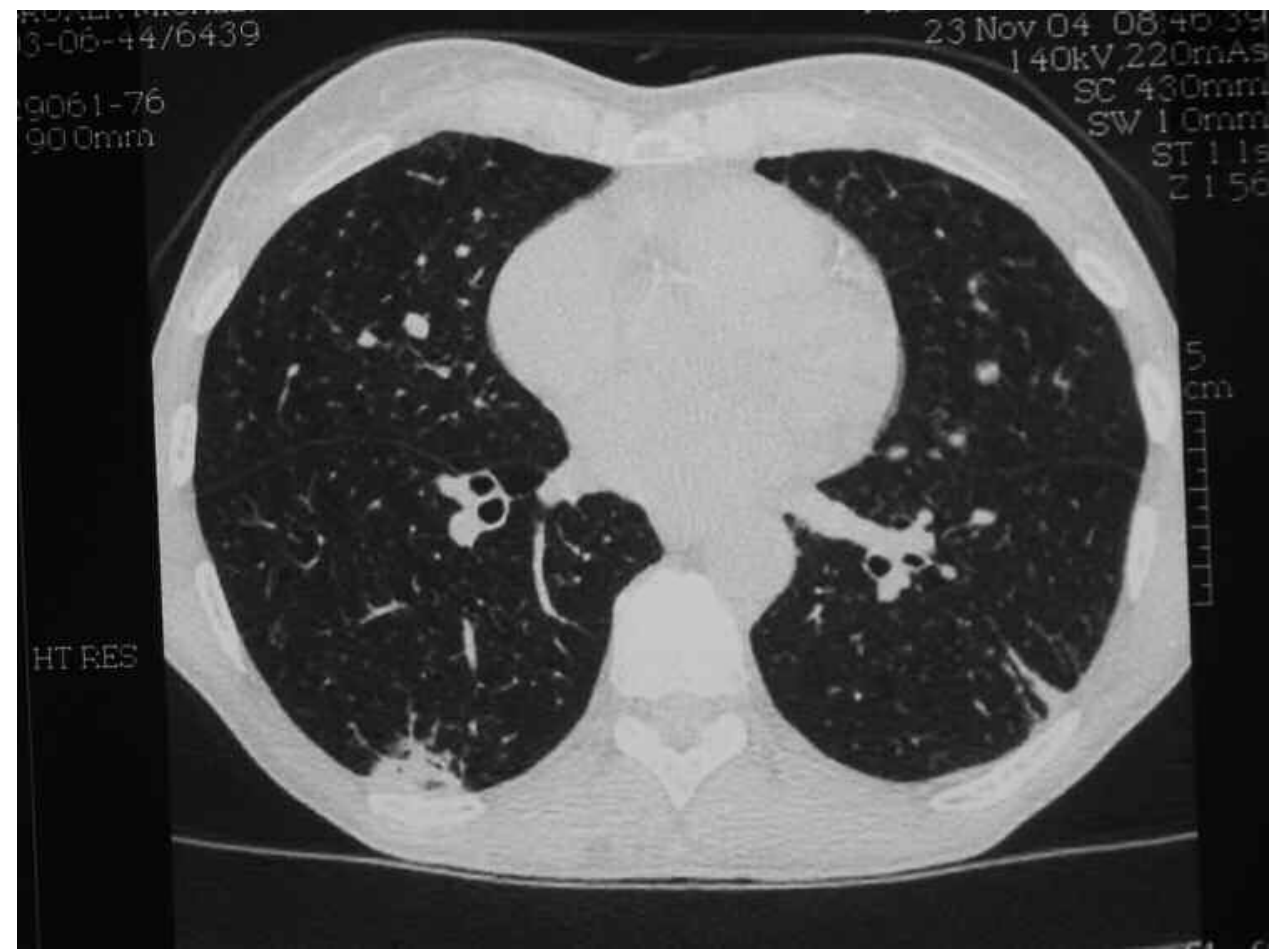

Figure 1B. November 2004; after 21 months of etanercept therapy.

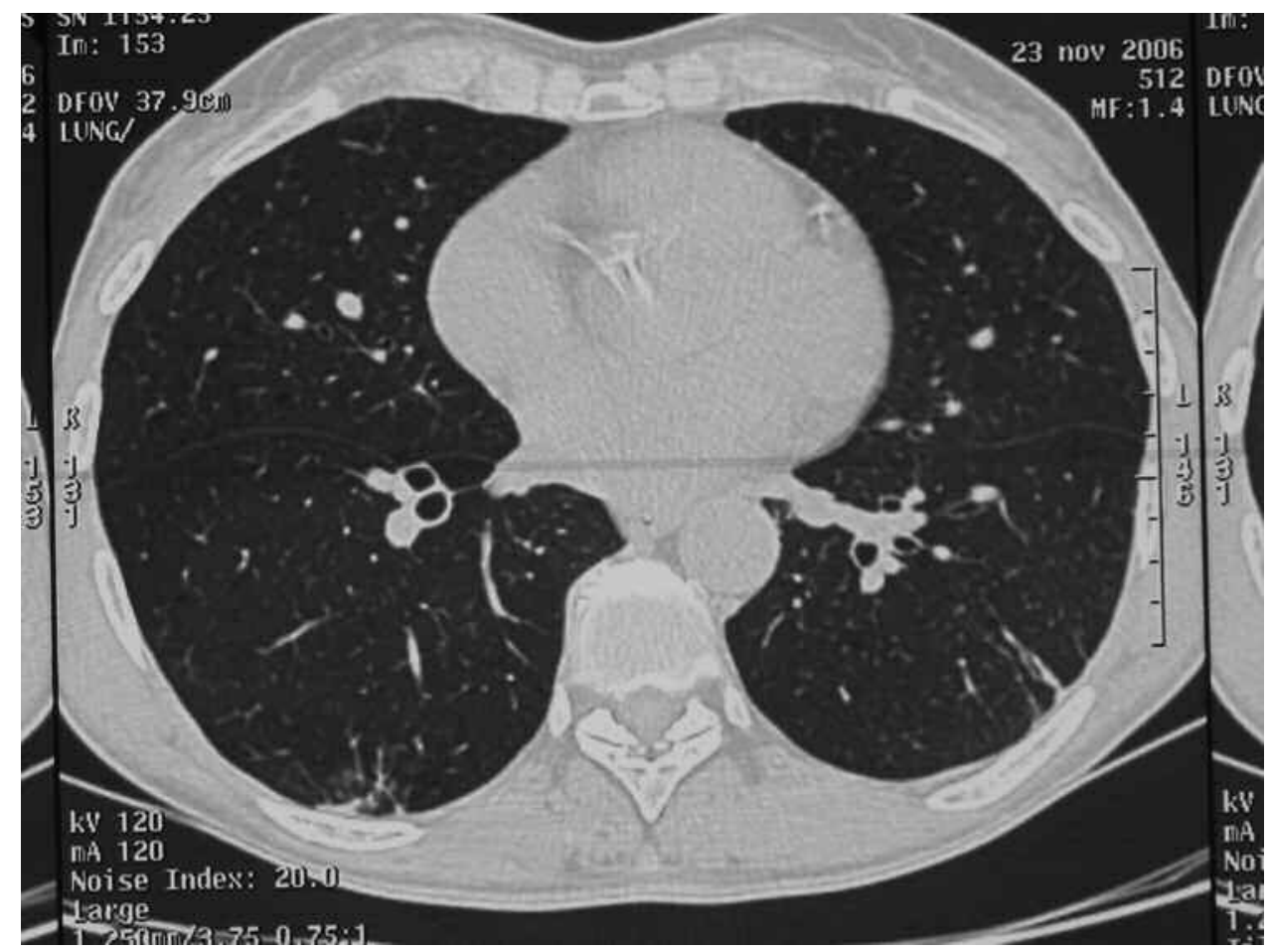

Figure 1C. November 2006; after 48 months of etanercept therapy.

2. Kaiser MJ, Bozonnat MC, Jorgensen C, Daurès JP, Sany J. Effect of etanercept on tenosynovitis and nodules in rheumatoid arthritis. Arthritis Rheum 2002;46:559-60.

3. Wikaningrum R, Highton J, Parker A, et al. Pathogenic mechanisms in the rheumatoid nodule: comparison of proinflammatory cytokine production and cell adhesion molecule expression in rheumatoid nodules and synovial membranes from the same patient. Arthritis Rheum 1998;41:1783-97. 


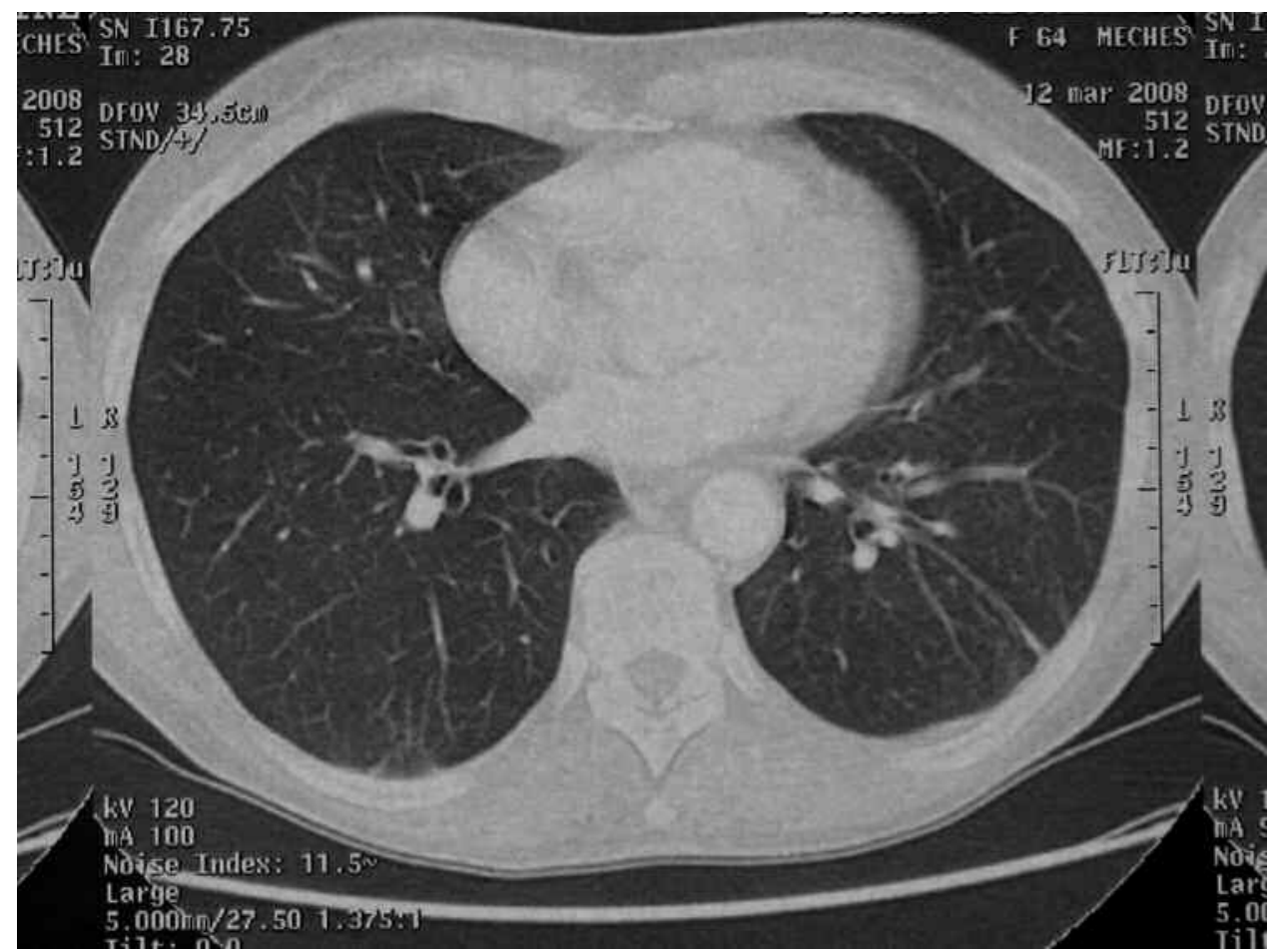

Figure 1D. March 2008; after 61 months of etanercept therapy. 